Meta

Journal des traducteurs

Translators' Journal

\title{
Comité d'étude des termes techniques français
}

\section{Robert Dubuc}

Volume 12, numéro 3, septembre 1967

URI : https://id.erudit.org/iderudit/017767ar

DOI : https://doi.org/10.7202/017767ar

Aller au sommaire du numéro

Éditeur(s)

Les Presses de l'Université de Montréal

ISSN

0026-0452 (imprimé)

1492-1421 (numérique)

Découvrir la revue

Citer ce document

Dubuc, R. (1967). Comité d'étude des termes techniques français. Meta, 12(3),

97-97. https://doi.org/10.7202/017767ar d'utilisation que vous pouvez consulter en ligne.

https://apropos.erudit.org/fr/usagers/politique-dutilisation/ 


\section{Comité d'étude des termes techniques français}

Fidèle à sa méthode de travail, le Comité d'étude des termes techniques français vient de lancer auprès de la presse spécialisée et technique de la francophonie une nouvelle consultation portant sur un certain nombre d'expressions techniques anglo-saxonnes. Pour chacune, le Comité établit une fiche provisoire où il circonserit le problème et propose une traduction qu'il motive ensuite do façon fort judicieuse. On reconnaît facilement dans ce travail les principes dont s'inspire le Comité : motivation des néologismes, possibilités de dérivation, transparence des équivalents proposés par rapport à l'expression-source. Il en résulte un travail terminologique de grande valeur tant sur le plan technique que sur le plan linguistique.

On ne peut que regretter que, devant un travail d'une telle qualité, l'industrie se montre en général si réticente. La fascination de l'emprunt continue à subjuguer la langue technique. Prenons le cas de bulldozer, qu'on se refuse à traduire - en invoquant l'autorité du Petit Larousse. Le Comité a proposé en 1955 de rendre ce terme par boutoir. Cette solution simple et élégante permet de résoudre du même coup tous les problèmes de traduction que posent les dérivés de bulldozer: angledozer devient boutoir oblique, calf dozer, boutoir léger, tiltdozer, boutoir à dévers, track driven dozer, boutoir à chenilles. Le maintien de bulldozer constitue un exemple patent de l'appauvrissement de la langue par l'abus de l'emprunt. Ce cas est loin d'être unique.

Ces fiches de consultation nous donnent un avant-goût prometteur de l'édition définitive qu'elles annoncent. Nous ne pouvons que souhaiter au travail $d u$ Comité d'étude des termes techniques la diffusion la plus large possible pour qu 'il puisse briser le mur de l'ignorance et du préjugé, causes les plus fréquentes de l'anglicisation de la langue technique. Pour la terminologie française, ces travaux constituent une véritable mine d'or.

Robert Dubuc

COMITÉ D'ÉTUde DES TERMES DE MÉDECINE, Vocabulaire de la langue des assurances sociales et des assemblées délibérantes, Montréal, Laboratoires Ayerst, 1967.

En présentant le deuxième volume des travaux du Comité d'étude des termes de médecine, les Laboratoires Ayerst renouvellent leur appui au Comité et répètent un geste de relations publiques dont la noblesse ne diminue certes pas la valeur commerciale.

La toilette graphique de ce Vocabulaire est aussi soignée que celle du premier volume, le Glossaire des termes médico-hospitaliers ${ }^{1}$. On y trouve d'abord le 1. Cf. META, vol. 11, no 4, p. 169. 